\title{
Correction to: Hormonal receptors in cutaneous vascular malformations: 51 cases
}

\author{
Sarah Ventéjou ${ }^{1,2} \cdot$ M.-C. Machet $^{1,3} \cdot$ D. Herbreteau ${ }^{1,4,5} \cdot$ A. le Touze ${ }^{5,6} \cdot$ G. Lorette ${ }^{1,2,5} \cdot$ A. Maruani ${ }^{1,2,5}$
}

Published online: 19 March 2019

(C) Springer-Verlag GmbH Germany, part of Springer Nature 2019

\section{Correction to: Virchows Archiv \\ https://doi.org/10.1007/s00428-019-02546-4}

The original version of this article contained error. Table 2 was shown in the wrong version, thus corrected table is shown in this article. The original article has been corrected.

The online version of the original article can be found at https://doi.org/ 10.1007/s00428-019-02546-4

Sarah Ventéjou

sarahventejou@orange.fr

1 University of Tours, 37000 Tours, France

2 Department of Dermatology, University Hospital Center (CHRU) of Tours, Avenue de la République, 37044 Tours CEDEX 9, France

3 Department of Pathology, University Hospital Center (CHRU) of Tours, 37000 Tours, France

4 Department of Neuroradiology, University Hospital Center (CHRU) of Tours, 37000 Tours, France

5 Reference Center for Rare Dermatologic Diseases (MAGEC) Vascular Malformations and Mosaicism, CHRU Tours, 37000 Tours, France

6 Department of Pediatric Surgery, University Hospital Center (CHRU) of Tours, 37000 Tours, France 
Table 2 Expression of hormonal receptor and triggering factors

\begin{tabular}{|c|c|c|c|c|c|c|c|c|}
\hline & \multirow[t]{2}{*}{$n$} & \multirow[t]{2}{*}{$\begin{array}{l}\text { Age at sampling, } \\
\text { years mean } \pm \mathrm{SD}\end{array}$} & \multirow[t]{2}{*}{$\begin{array}{l}\text { Estrogen receptor } \\
\text { expression } n(\%)\end{array}$} & \multirow[t]{2}{*}{$\begin{array}{l}\text { Progesterone receptor } \\
\text { expression } n(\%)\end{array}$} & \multicolumn{2}{|c|}{$\begin{array}{l}\text { Androgen receptor } \\
\text { expression } n(\%)\end{array}$} & \multicolumn{2}{|c|}{$\begin{array}{l}\text { Hormonal triggering } \\
\text { factors } n(\%)\end{array}$} \\
\hline & & & & & + & ++ & $\mathrm{AR}+$ & $\mathrm{AR}-$ \\
\hline \multirow[t]{2}{*}{ CLM } & \multirow[t]{2}{*}{13} & \multirow[t]{2}{*}{$7.2 \pm 5.3$} & \multirow[t]{2}{*}{0} & \multirow[t]{2}{*}{0} & $11(84.6)$ & & \multicolumn{2}{|l|}{$1(7.7)$} \\
\hline & & & & & $7(53.8)$ & $4(30.8)$ & 1 & 0 \\
\hline VeM & 16 & $9.0 \pm 3.5$ & 0 & 0 & $\begin{array}{l}12(75) \\
4(25)\end{array}$ & $8(50)$ & 0 & \\
\hline \multirow[t]{2}{*}{ AVM } & \multirow[t]{2}{*}{11} & \multirow[t]{2}{*}{$29.7 \pm 22.8$} & \multirow[t]{2}{*}{0} & \multirow[t]{2}{*}{0} & $8(72.2)$ & & \multicolumn{2}{|l|}{$4(36.4)$} \\
\hline & & & & & $5(45.5)$ & $3(27.2)$ & 1 & 3 \\
\hline \multirow[t]{2}{*}{ Others: } & \multirow[t]{2}{*}{11} & \multirow[t]{2}{*}{$15.5 \pm 12.4$} & \multirow[t]{2}{*}{0} & \multirow[t]{2}{*}{0} & $7(63.6)$ & & 1 & \\
\hline & & & & & $2(18.1)$ & $5(45.4)$ & 1 & 0 \\
\hline Gorham & 1 & 12.1 & & & & 1 & & \\
\hline PROS & 4 & 24.1 & 0 & 0 & & 2 & & \\
\hline MLT & 1 & 0 & 0 & 0 & & & & \\
\hline PWS & 1 & 9.2 & 0 & 0 & & & & \\
\hline $\mathrm{CLM}+\mathrm{VeM}$ & 2 & 7.4 & 0 & 0 & 1 & 1 & & \\
\hline $\mathrm{CM}+\mathrm{CLM}+\mathrm{VeM}$ & 2 & 13.5 & 0 & 0 & 1 & 1 & 1 & \\
\hline \multirow[t]{2}{*}{ Total } & \multirow[t]{2}{*}{51} & \multirow[t]{2}{*}{$14.4 \pm 15.0$} & \multirow[t]{2}{*}{0} & \multirow[t]{2}{*}{0} & $38(74.5)$ & & $6(11.8)$ & \\
\hline & & & & & $18(35.3)$ & $20(39.2)$ & 3 & 3 \\
\hline
\end{tabular}

$C L M$ cystic lymphatic malformation, $V e M$ venous malformation, $A V M$ arteriovenous malformation

PROS PIK3CA-related growth spectrum, MLT lymphangio-endotheliomatosis with thrombopenia, PWS Parkes-Weber syndrome, $C L M+V e M$ combined lymphatico-venous malformation, $C M+C L M+V e M$ capillaro-lymphatico-venous malformation, + slight expression, ++ strong expression, $A R+$ positive for androgen receptor, $A R-$, negative for androgen receptor

Publisher's note Springer Nature remains neutral with regard to jurisdictional claims in published maps and institutional affiliations. 